Revue internationale de l'économie sociale

Recma

\title{
La société coopérative européenne, une nouvelle dimension pour les coopératives
}

\section{Jean-Claude Detilleux}

Numéro 291, février 2004

La société coopérative européenne : colloque du GNC, 23 septembre 2003

The European Cooperative Society: The GNC Symposium on 23

September 2003

URI : https://id.erudit.org/iderudit/1022117ar

DOI : https://doi.org/10.7202/1022117ar

Aller au sommaire du numéro

Éditeur(s)

Institut de l'économie sociale (IES)

\section{ISSN}

1626-1682 (imprimé)

2261-2599 (numérique)

Découvrir la revue

Citer cet article

Detilleux, J.-C. (2004). La société coopérative européenne, une nouvelle dimension pour les coopératives. Revue internationale de l'économie sociale,

(291), 19-21. https://doi.org/10.7202/1022117ar d'utilisation que vous pouvez consulter en ligne. 


\section{LA SOCIÉTÉ COOPÉRATIVE EUROPÉENNE, UNE NOUVELLE DIMENSION POUR LES COOPÉRATIVES}

par Jean-Claude Detilleux ${ }^{(*)}$

(*) Président du Groupement national de la coopération (GNC).

(1) Règlement (CE) $n^{\circ} 1435 / 2003$ et directive 2003/72/CE, JOCE L 207 du 18 août 2003. II est à noter que le texte du règlement contient probablement une erreur de traduction, en faisant référence à la SEC, alors que la directive utilise l'abréviation SCE, qui elle est correcte.

(2) Affaire C-436/03, JOCE C 289 du 29 novembre 2003. 'adoption de la société coopérative européenne (SCE) le 22 juillet 2003 par le Conseil des ministres de l'Union européenne est un progrès important pour les mouvements coopératifs européens et le fruit de nombreuses années de discussions. Ce statut est basé sur deux textes juridiques: un règlement européen sur le statut lui-même et une directive relative à l'implication des travailleurs ${ }^{(1)}$.

Le statut de la société coopérative européenne répond à un double objectif: affirmer la spécificité des coopératives et leur permettre de prendre toute leur place dans les évolutions économiques à venir. Avec l'élargissement de l'Union européenne, ces objectifs prennent une importance nouvelle.

Dès août 2006, après transposition de la directive par les Etats membres, les premières sociétés coopératives européennes pourront être constituées et développer leur activité transnationale au sein d'une personne juridique unique. L'Union européenne lève ainsi l'un des obstacles à la libre concurrence et à la liberté d'établissement auxquels étaient confrontées les entreprises coopératives qui souhaitaient développer leurs activités dans un autre Etat membre. Elles vont pouvoir lutter à armes égales avec leurs concurrents du privé, sans avoir à se banaliser.

Surtout, l'adoption du statut a une signification politique forte. Elle marque la reconnaissance par l'Union européenne de la pertinence du modèle coopératif. La coopération fait aujourd'hui partie de l'acquis communautaire. Ce message revêt une importance particulière à l'égard notamment des futurs Etats membres, qui ne disposent pas tous d'une législation élaborée dans le domaine coopératif et qui pourront s'appuyer sur le statut de la SCE.

Les nombreuses années de travaux qui ont abouti à l'adoption du statut ont rassemblé les organisations coopératives nationales et européennes autour d'un projet, conçu initialement en leur sein. Grâce à leur engagement et à leur ténacité, ce projet a été porté par un nombre croissant d'acteurs au sein des institutions européennes et des Etats membres pour être aujourd'hui partie intégrante de l'édifice européen.

Mais nous ne sommes pas encore tout à fait au bout du long chemin qui a mené à l'adoption du statut. Le 15 octobre 2003, le Parlement européen a saisi la Cour de justice des Communautés européennes (CJCE) d'un recours contre la décision du Conseil des ministres ${ }^{(2)}$. Ce dernier a retenu 
comme base juridique pour l'adoption du règlement relatif au statut de la SCE l'article $308 \mathrm{CE}$, qui prévoit une décision unanime du Conseil après consultation du Parlement européen. Le Parlement considère que le règlement aurait dû être fondé sur l'article $95 \mathrm{CE}$, qui implique une procédure de codécision, donnant ainsi plus de poids au Parlement dans le processus législatif et pondérant celui du Conseil des ministres, qui se prononce à la majorité qualifiée.

Cet appel n'est pas suspensif et, quelle que soit la durée de la procédure devant la CJCE, le règlement s'appliquera de façon certaine en 2006. Il n'y a donc pas d'incertitude juridique quant à la possibilité future de constituer une SCE. Par ailleurs, en cas de décision de la CJCE favorable au Parlement européen, la réglementation actuelle s'appliquera jusqu'à l'entrée en vigueur d'une nouvelle réglementation.

En effet, il se peut, en cas d'annulation du règlement par la CJCE conformément à la demande du Parlement européen, que la Commission européenne soit amenée à présenter une nouvelle proposition de règlement, fondée sur la base juridique appropriée. Une telle proposition ne pourra que très largement reprendre les termes du texte actuel qui, rappelons-le, a été adopté à l'unanimité au sein du Conseil des ministres, et avec le soutien du Parlement européen.

Un tel scénario ne saurait inquiéter les mouvements coopératifs qui se verraient offrir la possibilité d'introduire des améliorations au texte actuel, amendements qu'ils ont délibérément préféré ne pas présenter lors de la relance des discussions sur la SCE qui a suivi le sommet européen de Nice, afin de ne pas risquer de retarder l'adoption de leur statut. Ils étaient alors convenus de demander une révision du texte dans les cinq ans suivant son application.

Ainsi, la procédure d'appel ne remet pas en question les avancées et grandes orientations proposées par le statut de la SCE adopté en juillet 2003.

Le 23 septembre 2003, le Groupement national de la coopération (GNC) a consacré son séminaire juridique annuel au thème de " La SCE, une nouvelle opportunité juridique à découvrir ", explorant les divers aspects qui y sont liés, historique, analyse juridique détaillée des textes, témoignage d'une expérience étrangère et perspectives offertes par ces nouveaux textes.

Depuis quatre ans, chaque édition du séminaire est l'occasion pour le GNC de rassembler enseignants, chercheurs, étudiants, juristes et représentants des mouvements qui se consacrent au droit coopératif.

En tant que rassemblement des mouvements coopératifs en France, le GNC a le souci de promouvoir l'enseignement universitaire et la recherche en droit coopératif. Le séminaire juridique annuel s'inscrit dans les actions entreprises à cet effet, à côté de l'animation de la partie juridique de son site Web, et d'autres actions entreprises en partenariat avec les professeurs, organisation de conférences et conventions Cifre par exemple.

Le dossier consacré par la Recma à la SCE reprend trois interventions qui ont été présentées à l'occasion du séminaire consacré à la SCE. 
Chantal Chomel, directrice du département législatif et réglementaire de Coop de France, retrace «la longue marche » qui a mené à l'adoption de la SCE et souligne le rôle joué par les différents acteurs qui ont été parties prenantes à ce débat, aux niveaux national et européen.

Brigitte Zago-Koch, adjointe au bureau Droit des salariés au ministère des Affaires sociales et de l'Emploi, présente les dispositions de la directive relative à l'implication des travailleurs, texte trop souvent méconnu par les juristes et pourtant indissociable du règlement relatif à la SCE.

Gilbert Parléani, professeur de droit à l'université de Paris-I, analyse le règlement et l'articulation du droit communautaire et des droits nationaux, sujet central pour les futurs porteurs de projets de SCE.

Nous sommes heureux de publier les travaux de notre séminaire dans la Recma, revue scientifique qui tout au long de son histoire a contribué, par la qualité et le niveau de ses contributions, à la promotion de l'économie sociale en général et des coopératives en particulier. 